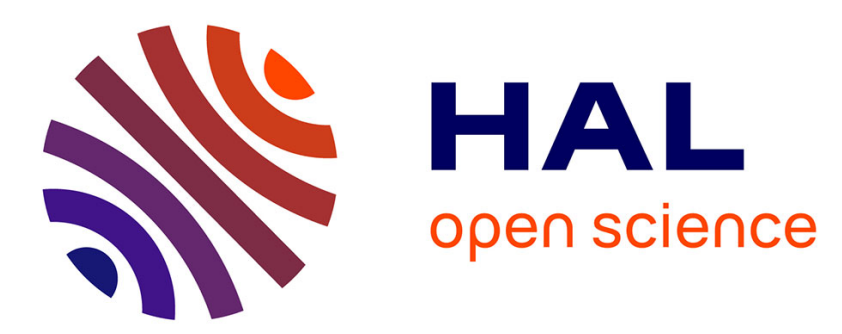

\title{
SiC coatings grown by liquid injection chemical vapor deposition using single source metal-organic precursors
}

Guilhaume Boisselier, Francis Maury, Frédéric Schuster

\section{To cite this version:}

Guilhaume Boisselier, Francis Maury, Frédéric Schuster. SiC coatings grown by liquid injection chemical vapor deposition using single source metal-organic precursors. Surface and Coatings Technology, 2013, vol. 215, pp. 152-160. 10.1016/j.surfcoat.2012.10.070 . hal-01218626

\section{HAL Id: hal-01218626 \\ https://hal.science/hal-01218626}

Submitted on 21 Oct 2015

HAL is a multi-disciplinary open access archive for the deposit and dissemination of scientific research documents, whether they are published or not. The documents may come from teaching and research institutions in France or abroad, or from public or private research centers.
L'archive ouverte pluridisciplinaire $\mathbf{H A L}$, est destinée au dépôt et à la diffusion de documents scientifiques de niveau recherche, publiés ou non, émanant des établissements d'enseignement et de recherche français ou étrangers, des laboratoires publics ou privés. 


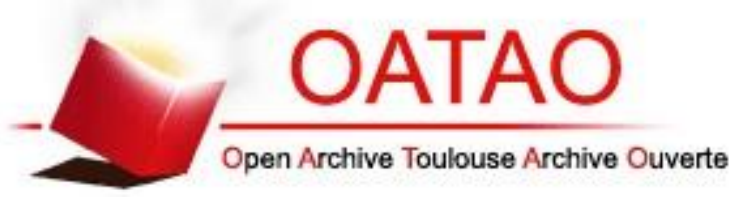

\section{Open Archive Toulouse Archive Ouverte (OATAO)}

OATAO is an open access repository that collects the work of Toulouse researchers and makes it freely available over the web where possible.

This is an author-deposited version published in: http://oatao.univ-toulouse.fr/ Eprints ID: 14097

To link to this article: DOI:10.1016/j.surfcoat.2012.10.070

URL: http://dx.doi.org/10.1016/j.surfcoat.2012.10.070

\section{To cite this version:}

Boisselier, Guilhaume and Maury, Francis and Schuster, Frédéric SiC coatings grown by liquid injection chemical vapor deposition using single source metal-organic precursors. (2013) Surface and Coatings Technology, vol. 215. pp. 152-160. ISSN 0257-8972

Any correspondence concerning this service should be sent to the repository administrator: staff-oatao@ listes.diff.inp-toulouse.fr 


\title{
SiC coatings grown by liquid injection chemical vapor deposition using single source metal-organic precursors
}

\author{
G. Boisselier ${ }^{\text {a }}$, F. Maury ${ }^{\mathrm{a}, *}$, F. Schuster $^{\mathrm{b}}$ \\ a CIRIMAT, CNRS/INPT/UPS, 4 allée E. Monso, BP 44362, 31030 Toulouse cedex 4, France \\ b CEA Saclay, DEN/DIR, 91191 Gif Sur Yvette, France
}

Keywords:

Silicon carbide

Amorphous SiC coatings

DLICVD

Hard coatings

Organosilane precursors

\begin{abstract}
A B S T R A C T
SiC coatings have been grown by direct liquid injection of organosilanes in a hot-wall chemical vapor deposition reactor (DLICVD). 1,3-disilabutane (DSB) and polysilaethylene (PSE) were used as single-source precursors. Amorphous and stoichiometric SiC coatings were deposited under low pressure on various substrates in the temperature range of $923-1073 \mathrm{~K}$. Thickness gradients due to the temperature profiles and the precursor depletion were observed along the reactor axis but the thickness uniformity could be improved as a function of the deposition conditions. Growth rates as high as $90 \mu \mathrm{m} \cdot \mathrm{h}^{-1}$ were obtained using pure precursors. The injection of PSE solutions in toluene significantly reduces the deposition rate due to the decrease of the PSE mole fraction but allows a better control of the growth rates and the microstructure of coatings. They exhibit a smooth surface morphology and a very dense structure. The films grown using pure precursors exhibit an Si:C atomic ratio equal to $1: 1$ while those using toluene solutions are slightly C-rich (54 at.\% C). The presence of solvent vapor in the CVD reactor becomes a source of carbon contamination at deposition temperatures equal to or higher than $1073 \mathrm{~K}$. The influence of the growth conditions is discussed, in particular the presence of toluene vapor.
\end{abstract}

\section{Introduction}

Silicon carbide $(\mathrm{SiC})$ is used in many fields as bulk or composite ceramic materials for structural applications and as coating for either the protection of a base material or its functional properties as thin film. Indeed, its semiconducting properties at high temperature make it a good candidate for power electronic components. Moreover, its high hardness and good thermal and chemical stability allow SiC to be used as wear and corrosion resistant coatings under severe environments.

Chemical vapor deposition (CVD) is a suitable process for the deposition of SiC thin films and also for the densification of the matrix of ceramic/ceramic composite materials. Different types of silicon and carbon precursors have been used. The best known $\mathrm{Si}$ sources are silane $\left(\mathrm{SiH}_{4}\right)$ and chlorosilanes $\left(\mathrm{SiCl}_{4-\mathrm{x}} \mathrm{H}_{\mathrm{x}}\right)$, coupled with different hydrocarbons like $\mathrm{C}_{3} \mathrm{H}_{8}$ as carbon source. Using these dual sources, $\mathrm{SiC}$ epitaxial layers can be achieved in the temperature range of 1473-2123 $\mathrm{K}$ using $\mathrm{H}_{2}$ as carrier gas either under low pressure [1] or atmospheric pressure [2,3]. SiC-based composite ceramic materials are usually performed by chemical vapor infiltration using methyl-trichlorosilane $\left(\mathrm{CH}_{3} \mathrm{SiCl}_{3}\right)$ and $\mathrm{H}_{2}$ as a source providing a $1: 1$ $\mathrm{Si}: \mathrm{C}$ atomic ratio but a $\mathrm{Si}$ excess in the coatings can be obtained [4]. This precursor was also used for the deposition of $\mathrm{SiC}$ protective

\footnotetext{
* Corresponding author. Tel.: + 33 534323401; fax: + 33534323499 E-mail address: francis.maury@ensiacet.fr (F. Maury).
}

coatings under low pressure between 1073 and $1373 \mathrm{~K}$ [5], and for the growth of epitaxial layers at higher temperature (1373-1503 K), in both cases using $\mathrm{H}_{2}$ as carrier gas [6].

Chlorine-free organosilane compounds are a particular family of precursors developed over the past 20 years. The great interest on these metal-organic molecules is that they can be used as singlesource precursors because they both offer $\mathrm{Si}$ and $\mathrm{C}$ atoms in the same molecule and contain already formed $\mathrm{Si}-\mathrm{C}$ bonds [7]. Consequently, among their advantages, they allow simplifying the CVD conditions (e.g. only one flow rate of reactant has to be controlled) and developing low temperature processes due to their lower thermal stability. Obviously, the film composition depends on the selection of the precursors. For instance, the use of $\mathrm{SiEt}_{4}\left(\mathrm{Et}=\mathrm{C}_{2} \mathrm{H}_{5}\right)$ produces surprisingly $\mathrm{Si}$-rich $\mathrm{SiC}$ films though the $\mathrm{Si}: \mathrm{C}$ atomic ratio in the starting molecule is $1: 8$ as a result of the kinetic lability of Et groups [8]. However, the film composition can be controlled using a hydrocarbon as co-reactant to get 1:1 or C-rich SiC coatings [9], and even for the growth of compositionally modulated $\mathrm{Si}_{\mathrm{x}} \mathrm{C}_{1-\mathrm{x}}$ layers [10].

More recently, suitably tailored polycarbosilanes containing the $\left[-\mathrm{SiH}_{2}-\mathrm{CH}_{2}-\right]$ unit and forming a regularly alternating backbone structure were proposed as CVD precursors with the advantage of a $\mathrm{Si}: \mathrm{C}$ atomic ratio of 1:1 identical to SiC. For instance, 1,3-disilabutane (DSB) $[11,12]$ and polysilaethylene (PSE) $[13,14]$ have been used in low pressure CVD processes in the temperature ranges of 923-1198 K and $1148-1273 \mathrm{~K}$, respectively, and using inert gas $\left(\mathrm{N}_{2}\right.$ or $\mathrm{Ar}$ ) or $\mathrm{H}_{2}$ as carrier gas (Table 1 ). These two precursors are liquid at room 
Table 1

Typical experimental CVD conditions for the growth of $\mathrm{Si}_{\mathrm{x}} \mathrm{C}_{1-\mathrm{x}}$ coatings using DSB and PSE as single-source molecular precursors.

\begin{tabular}{|c|c|c|c|c|}
\hline Precursors (empiric formula) & Deposition temperature (K) & Total pressure $(\mathrm{Pa})$ & Carrier gas & Reference \\
\hline \multirow[t]{3}{*}{ DSB $\left(\mathrm{CH}_{3}-\mathrm{SiH}_{2}-\mathrm{CH}_{2}-\mathrm{SiH}_{3}\right)$} & 1198 & 6.7 & $\mathrm{H}_{2}$ & [11] \\
\hline & $923-1173$ & $25-55$ & n.r. ${ }^{a}$ & {$[12]$} \\
\hline & $973-1073$ & 6667 & $\mathrm{~N}_{2}$ & This work \\
\hline \multirow[t]{4}{*}{$\operatorname{PSE}\left(\left[-\mathrm{SiH}_{2}-\mathrm{CH}_{2}-\right]_{\mathrm{n}}, \mathrm{n}=3-8\right)$} & 1148 & $133-400$ & $\mathrm{Ar}$ & [13] \\
\hline & 1273 & n.r. ${ }^{\mathrm{a}}$ & $\mathrm{N}_{2}$ & {$[14]$} \\
\hline & 973 & 6667 & $\mathrm{~N}_{2}$ & This work \\
\hline & $923-1073$ & $667 ; 6667$ & $\mathrm{~N}_{2}$ /toluene & This work \\
\hline
\end{tabular}

a n.r. means not reported.

temperature and exhibit a sufficient volatility, although relatively low in the case of PSE when the number of $[\mathrm{Si}-\mathrm{C}]$ units is near 8 (Table 2). Indeed, this last compound is a mixture of linear, branched and cyclic oligomers $[13,14]$. The low volatility limits the flow rate of precursor in the gas phase and then the growth rate of the CVD coatings.

On the other hand, pulsed direct liquid injection is an emerging technology for CVD processes (namely DLICVD) to deliver high flow rates of precursor vapor, even if they have a low volatility. This is required to develop large scale CVD reactors. Such processes are mainly used in microelectronics to deposit functional oxide thin films [15]. The growth of monolithic [16] and multilayer nanostructured chromium carbide and nitride coatings [17] was also reported by DLICVD. Regarding SiC coatings, a solution of hexamethyldisiloxane $\left(\left(\mathrm{CH}_{3}\right)_{3} \mathrm{SiOSi}\left(\mathrm{CH}_{3}\right)_{3}\right)$ in ethanol was injected by a DLI system in a plasma-assisted CVD reactor for the growth of $\mathrm{SiC}$ and $\mathrm{SiN}_{\mathrm{x}} \mathrm{O}_{\mathrm{y}} \mathrm{C}_{\mathrm{z}}$ coatings, at $1023 \mathrm{~K}$, using thermal $\mathrm{Ar} / \mathrm{H}_{2}$ and $\mathrm{Ar} / \mathrm{H}_{2} / \mathrm{N}_{2}$ plasma, respectively [18]. Solutions of the solid compound 1,4-bis(trimethylsilyl)benzene in $n$-pentane, hexamethyldisilane or bis(trimethylsilyl)acetylene as solvents were used in a plasma-assisted liquid injection CVD process to grow SiC films at $573 \mathrm{~K}[19]$. No report was found on DLICVD of SiC without the high reactivity of $\mathrm{Ar} / \mathrm{H}_{2}$ plasma assistance.

This paper deals with thermal DLICVD of SiC coatings in a hot-wall horizontal reactor using DSB and PSE as single-source precursors. The goal is to develop $\mathrm{SiC}$ protective coatings on pieces of large sizes and complex shapes for various applications, particularly in the nuclear industry. For this purpose, new thermal CVD processes aiming at high deposition rates, large-scale capacity and relatively low deposition temperatures are investigated. High deposition rates are desired for processes with high throughput while moderate temperature are aimed in order to be compatible with CVD of other carbide materials for the production of future multilayer coatings based on these SiC layers as for instance SiC/HfC [20]. Pure DSB and PSE as well as solutions of PSE in toluene as solvent have been injected in a low pressure CVD reactor at temperatures in the range of 923-1073 K. The influence of the growth conditions, including the effect of the solvent vapor on the growth rate and thickness uniformity along the reactor, and on the structure and composition of the coatings is presented.

\section{Experimental}

The organosilanes DSB (purchased from Gelest) [21] and PSE (Starfire ${ }^{\circledR}$ CVD-4000) [13] were commercially available. These liquid compounds are flammable in air and moisture sensitive. They were used without further purification and, as recommended, they were handled in an Ar atmosphere of a glove-box. When pure precursors were used, fractions of approximately $5 \mathrm{~g}$ were transferred into small containers to be connected to the CVD set-up. They are highly soluble in toluene used as solvent for specific experiments. The DSB compound was used only as pure liquid precursor while PSE was used directly as pure precursor and as solutions in toluene. The PSE solutions in toluene were also prepared under inert atmosphere using a vacuum Ar manifold (Schlenk line), then they were stirred half an hour at room temperature. Two concentrations of PSE in toluene were prepared: 10 and $15 \mathrm{~g} \cdot \mathrm{dm}^{-3}$ for CVD runs performed at 6.7 and $0.67 \mathrm{kPa}$, respectively. The largest concentration compensated for the lower total pressure to maintain approximately the same partial pressure of the precursor. This most concentrated solution was used only in preliminary CVD runs.

The CVD set up consisted of different components aligned horizontally including liquid injectors, a mixing and vaporization chamber and a tubular quartz reactor. The reactor was connected to a vacuum pumping system and a device to treat exhaust gasses (scrubbers). The injector was supplied with liquid precursor from a $\mathrm{N}_{2}$ pressurized container (200 $\mathrm{kPa}$ ) and the pulsed spray was flash vaporized in a chamber heated at $473 \mathrm{~K}$ (Kemstream injection/atomization system). The vapor was transported into the deposition zone by $500 \mathrm{sccm}$ of $\mathrm{N}_{2}$. The growth was performed in a horizontal hot-wall CVD quartz reactor, $2.6 \mathrm{~cm}$ in diameter and $60 \mathrm{~cm}$ long. It was heated by a one-zone tubular furnace producing a typical isothermal length of about $20 \mathrm{~cm}$. The total pressure during the growth was automatically controlled and maintained constant at $6.7 \mathrm{kPa}$ for all experiments reported here. Preliminary CVD runs were performed at a lower total pressure of $0.67 \mathrm{kPa}$ but they are not commented in detail because the composition, morphology and structure of the coatings are not significantly different from the results obtained at $6.7 \mathrm{kPa}$.

The amount of precursor used for each run was computer monitored by the injection parameters. For DLICVD using pure precursors, the frequency and the opening time of the injector were $2 \mathrm{~Hz}$ and $0.5 \mathrm{~ms}$, respectively. From these injection conditions, the molecular flow rate $\left(\mathrm{F}_{i}\right)$ of the precursor $i$ can be determined according to Eq. (1):

$\mathrm{F}_{i}=\mathrm{d}_{i} * \mathrm{~V}_{i} / \mathrm{t} * \mathrm{M}_{i}$

where $d_{i}$ is the density of the precursor (Table 2 ), $V_{i}$ is the total volume of liquid precursor injected, $\mathrm{M}_{i}$ is its molecular weight $\left(90 \mathrm{~g} \cdot \mathrm{mol}^{-1}\right.$ for DSB and the arbitrary value $\mathrm{M}_{n}=2000$ for PSE that is a mixture of

Table 2

Physical properties of the molecular precursors and the solvent used in DLICVD of SiC coatings (all data in standard conditions, i.e. at $10^{5}$ Pa or $298 \mathrm{~K}$ ).

\begin{tabular}{lllllll}
\hline Precursors & m.p. $(\mathrm{K})^{\mathrm{a}}$ & b.p. $(\mathrm{K})^{\mathrm{a}}$ & Vapor pressure $(\mathrm{kPa})$ & f.p. $(\mathrm{K})^{\mathrm{a}}$ & ${\text { Density }\left(\mathrm{g} \cdot \mathrm{cm}^{-3}\right)}_{\text {Def. }}$ \\
\hline DSB & $<273$ & 317 & 54.1 & $<273$ & 0.674 & Dynamic viscosity $(\mathrm{mPa} \cdot \mathrm{s})$ \\
PSE & 233 & $343-423^{\mathrm{c}}$ & 0.67 & 282 & 0.885 & 1.52 \\
Toluene & 180 & 383 & 29.1 & 277 & 0.87 & {$[21,41]$} \\
\hline
\end{tabular}

a m.p. melting point; b.p. boiling point; f.p. flash point.

b n.r. means not reported.

c Values determined at $267 \mathrm{~Pa}$. 
linear, branched and cyclic oligomers according to [13,14,22]) and $t$ is the duration of the CVD run. Therefore, using pure precursors, the molecular flow rate of precursors was $1.98 * 10^{-3}$ and $1.12 * 10^{-4} \mathrm{~mol} \cdot \mathrm{min}^{-1}$ for DSB and PSE, respectively. When PSE solutions in toluene were used, the frequency and the opening time were $10 \mathrm{~Hz}$ and $0.5 \mathrm{~ms}$, respectively. Under these conditions, $95 \mathrm{~cm}^{3}$ of a solution of $10 \mathrm{~g} \cdot \mathrm{dm}^{-3}$ was injected in $75 \mathrm{~min}$, which corresponds to a molecular flow rate of the PSE precursor of $6.3 * 10^{-6} \mathrm{~mol} \cdot \mathrm{min}^{-1}$, which is 18 times lower than using the pure PSE precursor. The thickness of the coatings was adjusted by the deposition time, which was, for instance at $973 \mathrm{~K}, 10 \mathrm{~min}$ and $20 \mathrm{~min}$ using DSB and PSE, respectively, as pure precursors and $75-155 \mathrm{~min}$ for the PSE solutions in toluene of $10 \mathrm{~g} \cdot \mathrm{dm}^{-3} \cdot \mathrm{Si}(100)$ wafers $\left(10 * 15 * 0.4 \mathrm{~mm}^{3}\right)$ and small graphite plates $\left(17 * 14 * 3 \mathrm{~mm}^{3}\right)$ were used as substrates. The graphite was of grade 2333 from Carbone Lorraine Composants (density $1.86 \mathrm{~g} \cdot \mathrm{cm}^{-3}$; coefficient of thermal expansion $6.0 * 10^{-6}{ }^{\circ} \mathrm{C}^{-1}$ ). They were ultrasonically cleaned in ethanol and then placed along the longitudinal axis of reactor. Prior to the deposition, the set up was vacuum purged for a few hours using a turbomolecular pump $\left(10^{-2} \mathrm{~Pa}\right)$.

The coating morphology has been characterized by scanning electron microscopy (SEM). The surface roughness was measured using an optical surface profiler (a white light interferometer, NewView 100 model of Zygo). The chemical composition was analyzed by electron probe microanalysis (EPMA) using the model SX50 of Cameca. Secondary ion mass spectrometry (SIMS) was performed by analyzing positive secondary ions in high resolution mode using $\mathrm{Cs}^{+}$bombardment (Cameca IMS 4F6 spectrometer). The coating structure was determined by X-ray diffraction (XRD) over the $2 \theta$ angular range of $10-80^{\circ}$ using a Seifert XRD 3000TT apparatus either in the Bragg-Brentano configuration ( $\mathrm{Cu} \mathrm{K} \mathrm{K}_{\alpha(1+2)}$ radiation, equipped with a diffracted beam graphite monochromator) or at grazing incidence $\left(4^{\circ}\right)$ depending on the film thickness. The total content of hydrogen in the films has been determined by Elastic Recoil Detection Analysis (ERDA). Coatings grown on high-resistivity $\mathrm{Si}(100)$ wafer polished on both sides were analyzed by IR transmission using a Nicolet 5700 spectrometer in the frequency range of $400-4000 \mathrm{~cm}^{-1}$. The chemical environment of the elements constituting the coatings was investigated by X-ray photoelectron spectroscopy (XPS) using a monochromatized Al X-ray source (K-Alfa spectrometer from Thermo Scientific). As preliminary study of the mechanical properties, the hardness of some samples was determined by micro- and nano-indentation. Micro-indentation tests were performed on the thickest films using a Vickers diamond micro-indentor (Buehler Company) using loads from 0.05 to $1 \mathrm{~kg}$. The hardness and the Young modulus of a couple of coatings were determined from a series of indentations employing a nano-indenter instrument (CSM Instrument) equipped with a Berkovich indenter. The tests were conducted using indentation loads of $20 \mathrm{mN}$ for $30 \mathrm{~s}$. The data were treated according to the method of Oliver and Pharr [23].

\section{Results}

A particularity of horizontal hot-wall CVD reactor is that there is an isothermal zone (here $c a .20 \mathrm{~cm}$ long between the coordinates 23 and $43 \mathrm{~cm}$ from the entrance) and two non-isothermal zones on both sides at the entrance and outlet of the reactor. As a result a depletion effect of the precursor occurs as its consumption increases along the reactor due to the gas phase decomposition and the growth of the coating. Consequently, the local CVD conditions near the substrates, i.e. temperature and precursor concentration, significantly change along the reactor. By contrast, depletion effects are strongly limited in cold-wall CVD reactors but up-scaling for production capacity is more limited. The growth was investigated as a function of the CVD parameters, essentially the nature of the precursor, the effect of a solvent, the local temperature (given by pre-established experimental charts) and the coordinate of the samples along the reactor from the gas inlet which is related to the local mole fraction of the precursor.

\subsection{Growth using pure DSB and PSE precursors}

SiC coatings were grown using pure DSB precursor between 973 and $1073 \mathrm{~K}$ at a total pressure of $6.7 \mathrm{kPa}$. At $973 \mathrm{~K}$, samples in the isothermal zone exhibit a heterogeneous surface morphology revealing a nodular growth which leads to a high surface roughness and a low density (Fig. 1a). This morphology is generally observed when adsorbed reactive species exhibit a low surface mobility, i.e. a slow surface diffusion resulting from a low deposition temperature. A cross section view clearly shows the high roughness $\left(R_{a}=2.9 \mu \mathrm{m}\right)$ and porosities (microvoids) in a coating of approximately $5 \mu \mathrm{m}$ thick (Fig. 1b). As frequently observed for this ceramic material, the CVD coatings grown on $\mathrm{Si}(100)$ show many cracks forming a network. They originate from residual stresses and in particular thermal stresses due to the difference of the expansion coefficient between the coating and the substrate. By increasing the deposition temperature to $1073 \mathrm{~K}$, the films are always cracked but they exhibit a smooth and uniform surface morphology and a high density (Fig. 1c). Due to the smoother surface morphology, the crack network is more visible than at lower temperature $(973 \mathrm{~K})$. The surface roughness $R_{a}$ of a coating of $1.5 \mu \mathrm{m}$ thick is only $77 \mathrm{~nm}$ (Fig. 1d).

The surface morphology of SiC films grown using pure PSE as starting material is very similar to one of the samples prepared with pure DSB (Fig. 2a). A 3D growth tends to be observed at low temperature as the result of the growth of several grains more or less perpendicularly to the surface. No evidence of $1 \mathrm{D}$ growth that would form fibers, tubes or rods was found. By comparing Figs. 1a and 2a, the surface roughness appears higher using pure PSE as precursor but this is due to the greater thickness of the coating. As for DSB precursor, the surface roughness significantly decreases and the density is improved by increasing the deposition temperature (Fig. 2b). With both precursors, by-products in the form of yellowish to brown powders were observed at the exit of the reactor on the cold part.

The variation of the growth rate along the CVD reactor is shown in Fig. 3 for runs performed at $973 \mathrm{~K}$ using both precursors. Observation of the reactor wall after deposition reveals that the onset temperature of deposition is approximately $910 \mathrm{~K}$ using DSB precursor. For this precursor, advancing along the reactor the growth rate increases to a maximum around $60 \mu \mathrm{m} \cdot \mathrm{h}^{-1}$ near the center of the reactor (local temperature $950 \mathrm{~K}$ ) and then it decreases slightly towards the exit as a result of the depletion of the DSB precursor. At the same furnace temperature, the profile of the growth rate along the reactor using pure PSE is also comparable (Fig. 3). The onset temperature of deposition is estimated at $915 \mathrm{~K}$ but the maximum of the growth rate peaks is at $90 \mu \mathrm{m} \cdot \mathrm{h}^{-1}$, which is significantly higher than using DSB precursor.

All the as-deposited films using pure DSB and PSE are X-ray amorphous. Their chemical composition was found stoichiometric in the isothermal zone and independent of the position of the sample in the reactor (Table 3 ).

\subsection{Growth using PSE solutions in toluene}

In preliminary experiments using PSE solutions in toluene, thin films were deposited at a total pressure of $0.67 \mathrm{kPa}$ in the temperature range of 923-948 K. The growth rate found at $923 \mathrm{~K}$ was low $\left(0.12 \mu \mathrm{m} \cdot \mathrm{h}^{-1}\right)$ and in good agreement with the fact that this temperature was near that of the onset of deposition mentioned above using pure PSE. In order to improve the decomposition rate of PSE precursor, the residence time of the species in the reactor was increased by increasing the total pressure and all subsequent runs were made at $6.7 \mathrm{kPa}$, as for pure precursors, between 973 and $1073 \mathrm{~K}$. 

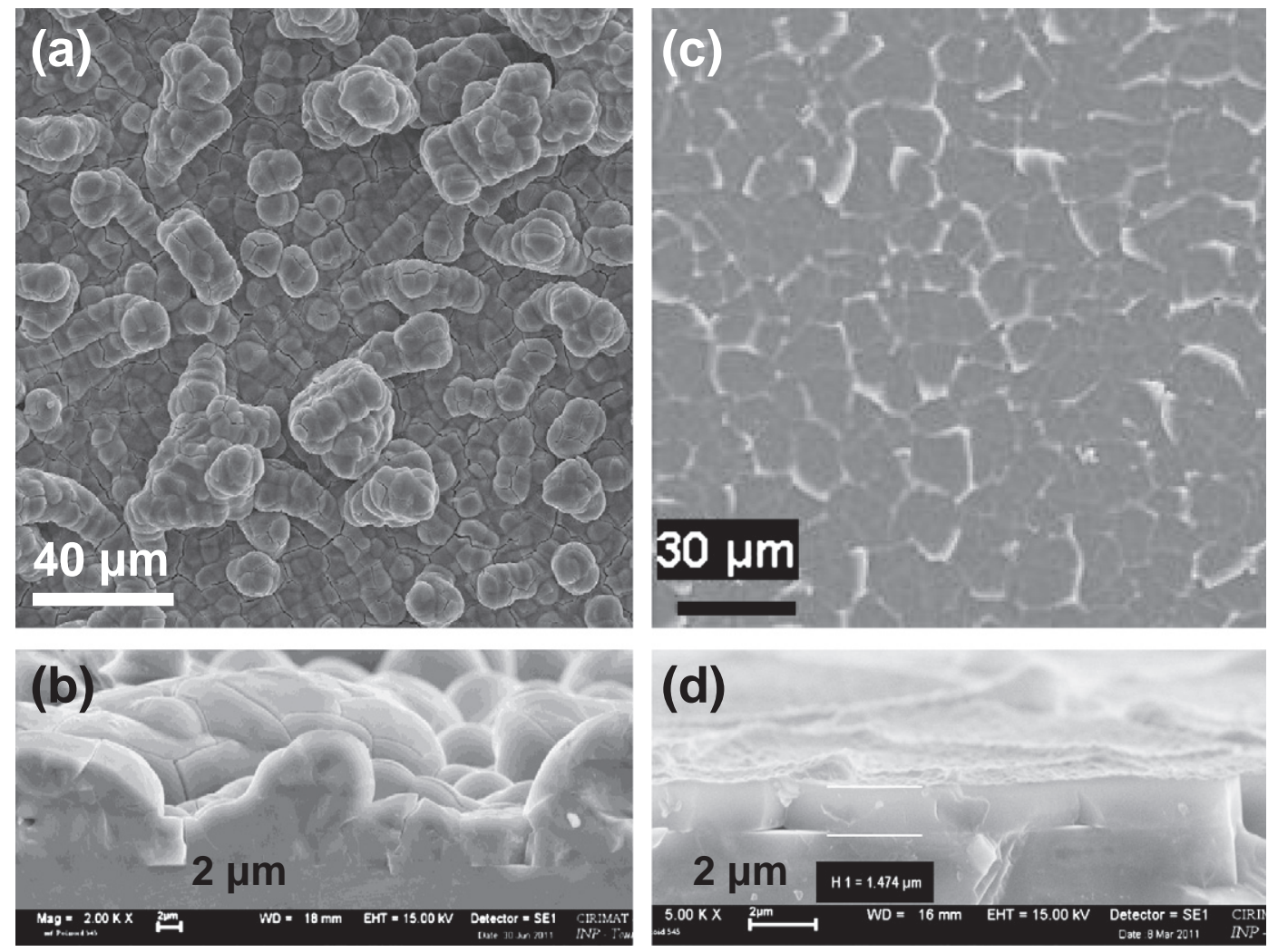

Fig. 1. SEM micrographs of SiC coatings grown by DLICVD on Si substrates at different temperatures using DSB precursor: (a) $973 \mathrm{~K}$, top view; (b) $973 \mathrm{~K}$, cross section; (c) $1073 \mathrm{~K}$, top view; (d) $1073 \mathrm{~K}$, cross section.

Samples in the isothermal zone prepared at $973 \mathrm{~K}$, exhibit a very smooth surface morphology, a high density and always an important network of microcracks (Fig. 2c, d). Nodular outgrowths emerge sometimes from the smooth surface. The average size of these heterogeneities is a few microns and their density of distribution over the surface is around $10^{4} \mathrm{~cm}^{-2}$. By increasing the deposition temperature to $1073 \mathrm{~K}$, the distribution density of these heterogeneities tends to decrease but this depends also on the coordinate of the samples along the reactor. SEM cross sections of coatings grown at $1073 \mathrm{~K}$ always exhibit a smooth surface morphology $\left(R_{a}=130 \mathrm{~nm}\right)$ and a high density (Fig. 2e). Apart from the many cracks that traverse the $\mathrm{SiC}$ film to the interface with the substrate, causing an early scaling in some areas, the adherence on Si seems pretty good. However, evidences for a better adherence of $\mathrm{SiC}$ coatings on graphite substrate were found from SEM cross section analysis even if microcracks are always present in the coatings on the graphite. A surface density of cracks defined as the relative area of open porosities created by the cracks per surface unit (given in \%) was measured from SEM top views using an image manipulation software. This surface density of cracks was estimated at $5 \% \pm 1 \%$ and it does not change between 973 and $1073 \mathrm{~K}$.

Fig. 4 shows the variation of the growth rate along the CVD reactor for different set temperatures. When the furnace temperature is set at 1023 and $1073 \mathrm{~K}$, the onset temperature of deposition is estimated at 978 and $1023 \mathrm{~K}$, respectively. For the set temperature of $973 \mathrm{~K}$, it was difficult to estimate the coordinate of the beginning of growth and then the onset temperature of deposition because of a diffused and hazy film that was formed over a relatively long distance. As using pure precursors, the growth rate passes through a maximum which is shifted upstream when the furnace temperature is increased from 973 to 1023 and $1073 \mathrm{~K}$. The maximum growth rate increases significantly with the set temperature from 1.4 to 5.6 and $9.9 \mu \mathrm{m} \cdot \mathrm{h}^{-1}$, respectively, indicating that the process is thermally activated.
Compared to the CVD run using pure PSE, the significant decrease in the maximum growth rate at $973 \mathrm{~K}$ is nearly in the proportions of the reduction of the molecular flow rate of the precursor. At $1073 \mathrm{~K}$, the maximum growth rate is near the center of the reactor and a depletion effect of the precursor is more strongly observed than at lower temperature.

As-deposited coatings deposited in the temperature range of 973-1073 K using PSE solutions in toluene are X-ray amorphous whatever the substrate (Si or graphite) is. The XRD patterns exhibit only a small and broad hump centered on the positions expected for the most intense peaks of cubic SiC (Fig. 5). After vacuum annealing at $1273 \mathrm{~K}$ for only ca. $30 \mathrm{~min}$, the (111), (220) and (311) peaks of cubic SiC clearly appeared, revealing a polycrystalline structure of the annealed coatings (Fig. 5). The peaks are broad and an average crystallite size of $c a .4 \mathrm{~nm}$ has been determined using the Scherrer method.

The composition of films grown using PSE solutions in toluene has been analyzed by EPMA for different set temperatures and coordinates of the samples along the reactor (Table 3 ). For all the coatings, the oxygen contamination is near the detection limit ( $\leq 1$ at.\%). At 973 and $1023 \mathrm{~K}$, the films are slightly C-rich (54 at.\% C) and their composition is uniform and independent of the position of the samples. At higher temperature $(1073 \mathrm{~K})$ in the first half of the reactor, the $C$ content is 53 at.\% and it increases downstream to reach typically 64 at.\% in the second half.

Fig. 6 shows a typical SIMS depth profile analysis of a sample grown at $973 \mathrm{~K}$ on a Si substrate. The flat profiles of $\mathrm{Si}, \mathrm{C}$ and $\mathrm{H}$ reveal that the distribution is very homogeneous through the film thickness. Traces of oxygen appear at the interface resulting likely from the native oxide of the Si substrate and a contamination of its surface prior to the deposition (hydrogen is also enhanced in this region). The composition of this sample determined by EPMA was $\mathrm{Si}_{0.47} \mathrm{C}_{0.52} \mathrm{O}_{0.01}$. Other SIMS profiles of samples grown at higher 

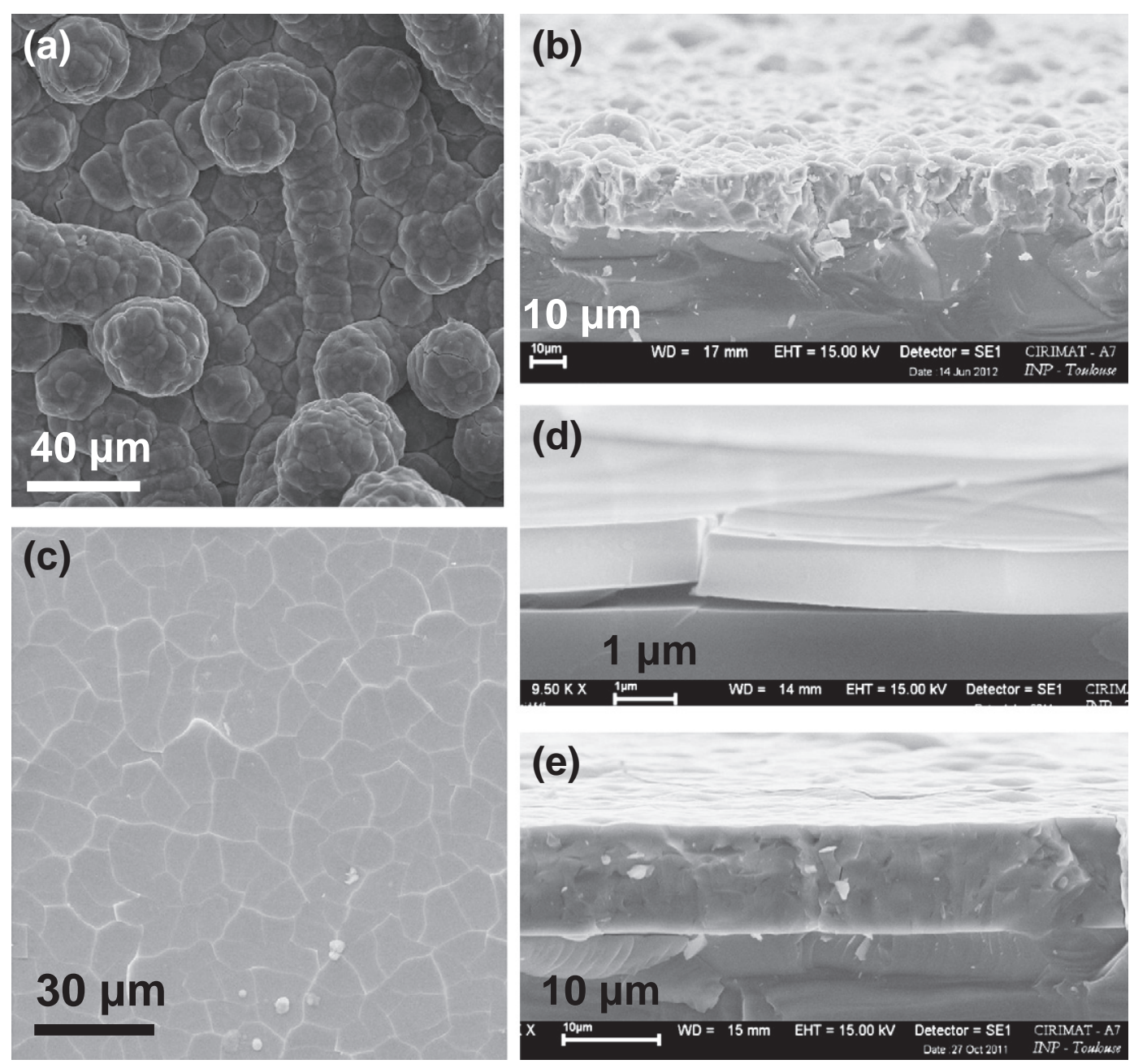

Fig. 2. SEM micrographs of SiC coatings grown by DLICVD on Si substrates using PSE precursor: (a) $973 \mathrm{~K}$, pure PSE, top view; (b) $1073 \mathrm{~K}$, pure PSE, cross section; (c) 973 K, PSE in toluene solution, top view; (d) $973 \mathrm{~K}$, PSE in toluene solution, cross section; (e) $1073 \mathrm{~K}$, PSE in toluene solution, cross section.

temperatures are very similar confirming the good uniformity of $\mathrm{Si}, \mathrm{C}$ and $\mathrm{H}$ through the entire thickness of the films.

Hydrogen is a chemical element frequently present in amorphous SiC films. The total amount of hydrogen determined by ERDA was 12 at. $\% 1$ for a coating as-deposited at $973 \mathrm{~K}$ on Si substrate. After

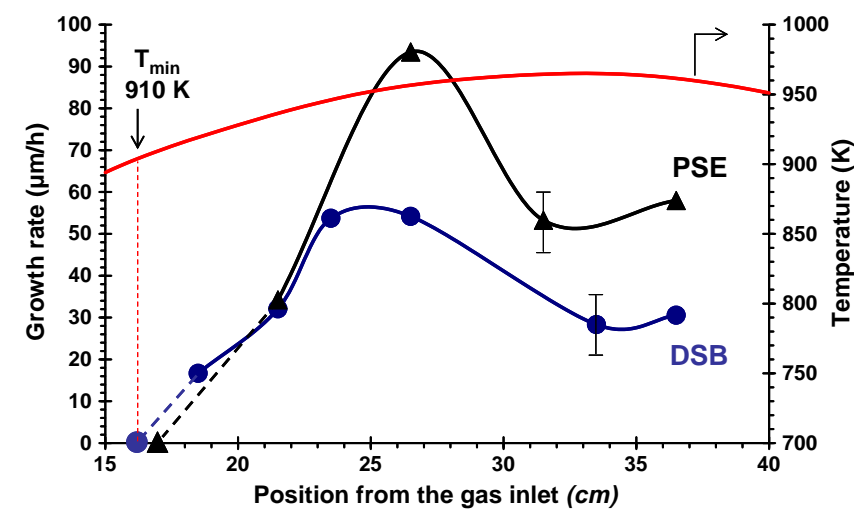

Fig. 3. Variation of the growth rate of SiC coatings along the DLICVD reactor using pure DSB $(\bullet)$ and pure PSE $(\boldsymbol{\Delta})$ at the set temperature of $973 \mathrm{~K}$ (total pressure $6.7 \mathrm{kPa}$ ). The temperature profile is also reported. The growth rate was determined from the weight gain of the samples. A typical uncertainty is indicated by an error bar. The curves are a guide for the eyes and they are extrapolated to the onset of deposition as observed on the quartz reactor. vacuum annealing at $1273 \mathrm{~K}$ for $\mathrm{ca} .30 \mathrm{~min}$, the total hydrogen content decreases to 5 at.\% \pm 1 . This gives evidence for a hydrogen release during the annealing, which results in crystallization of the coating (Fig. 5).

The concentration of hydrogen bonded to silicon, namely [Si-H], can be readily determined by transmission IR spectroscopy in

Table 3

Chemical composition (EPMA data) of $\mathrm{Si}_{\mathrm{x}} \mathrm{C}_{1-\mathrm{x}}$ coatings grown by DLICVD using pure DSB, pure PSE and a PSE solution in toluene as precursors. The compositions are given for different samples depending on the set temperature of the furnace and their position along the reactor axis from the gas inlet (total pressure $6.7 \mathrm{kPa}$ ).

\begin{tabular}{|c|c|c|c|c|c|}
\hline Precursor & $\begin{array}{l}\text { Set } \\
\text { temperature } \\
\text { (K) }\end{array}$ & $\begin{array}{l}\text { Position in the } \\
\text { reactor axis } \\
(\mathrm{cm})\end{array}$ & $\begin{array}{l}\text { Si content } \\
\text { (at.\%) }\end{array}$ & $\begin{array}{l}\text { C content } \\
\text { (at.\%) }\end{array}$ & $\begin{array}{l}\text { O content } \\
\text { (at.\%) }\end{array}$ \\
\hline \multirow[t]{2}{*}{ DSB } & \multirow[t]{2}{*}{973} & 19 & 53 & 47 & n.d. ${ }^{a}$ \\
\hline & & 34 & 51 & 49 & n.d. ${ }^{a}$ \\
\hline \multirow[t]{2}{*}{ PSE } & \multirow[t]{2}{*}{973} & 22 & 48 & 52 & n.d. ${ }^{a}$ \\
\hline & & 32 & 50 & 50 & n.d. ${ }^{a}$ \\
\hline \multirow[t]{7}{*}{ PSE/Toluene } & \multirow[t]{2}{*}{973} & 33 & 45 & 55 & n.d. ${ }^{a}$ \\
\hline & & 38 & 47 & 52 & 1 \\
\hline & \multirow[t]{2}{*}{1023} & 27 & 45 & 52 & 3 \\
\hline & & 38 & 46 & 53 & 1 \\
\hline & \multirow[t]{3}{*}{1073} & 27 & 45 & 53 & 2 \\
\hline & & 38 & 35 & 64 & 1 \\
\hline & & 43 & 35 & 64 & 1 \\
\hline
\end{tabular}

a Not determined because the value was near the detection limit estimated at $c a$. 1 at.\%. 


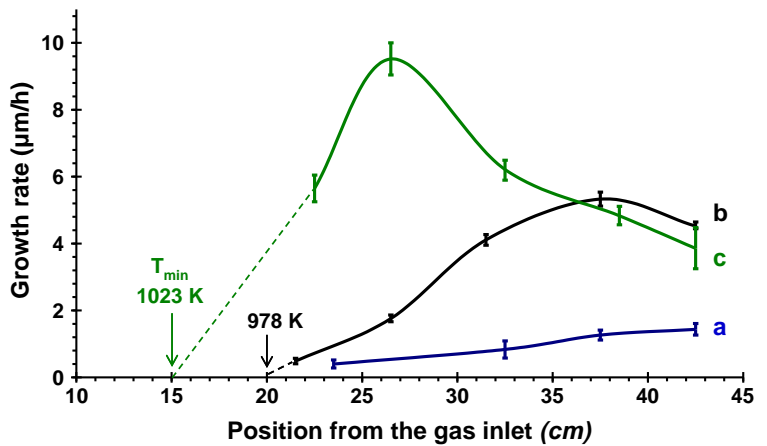

Fig. 4. Variation of the growth rate of SiC coatings along the DLICVD reactor using a PSE solution in toluene for different set temperatures: (a) $973 \mathrm{~K}$, (b) $1023 \mathrm{~K}$ and (c) $1073 \mathrm{~K}$ (total pressure $6.7 \mathrm{kPa}$ ). The growth rate was determined from thickness measurements on cross sections by SEM. The curves are a guide for the eyes and they are extrapolated to the onset of deposition as observed on the quartz reactor.

Si-based coatings according to the Lanford et al. method [24], applied later to reactive sputtering $a-\mathrm{SiC}: \mathrm{H}$ coatings [25]. IR spectra of films grown on $\mathrm{Si}(100)$ show an absorption band at $2103 \mathrm{~cm}^{-1}$ assigned to the $\mathrm{Si}-\mathrm{H}$ stretching modes. Using the IR absorption cross section previously reported $[24,25]$, a [Si-H] proportion of $0.9,0.6$ and 0.4 at.\% has been determined for coatings as-deposited at 973, 1023 and $1073 \mathrm{~K}$, respectively. This reveals a decrease of the number of $\mathrm{H}$ bonded to $\mathrm{Si}$ as the deposition temperature increases. So the concentration of $\mathrm{Si}-\mathrm{H}$ (ca. 1 at.\%) is lower than the total content of hydrogen (ca. 12 at.\%) for $a-S i C: H$ coating grown at $973 \mathrm{~K}$. In addition to the significant uncertainty of the IR method, the difference can be explained ( $i$ ) by the $\mathrm{H}$ bonded to $\mathrm{C}$, as evidenced by the $\mathrm{C}-\mathrm{H}$ stretching bands at 2845 and 2915 and a small shoulder at $2955 \mathrm{~cm}^{-1}$, and (ii) probably by molecular hydrogen trapped in microvoids as reported for $a-\mathrm{Si}: \mathrm{H}$ [26]. The $\mathrm{C}-\mathrm{H}$ stretching modes are more intense than $\mathrm{Si}-\mathrm{H}$ stretching bands suggesting that the number of $\mathrm{C}-\mathrm{H}$ bonds is higher than that of $\mathrm{Si}-\mathrm{H}$. In $a-\mathrm{SiC}: \mathrm{H}$ films grown by reactive sputtering a ratio $\mathrm{C}-\mathrm{H} / \mathrm{Si}-\mathrm{H}$ of about 3 was reported [25] in good agreement with the results on pyrolytic conversion to SiC starting from PSE precursor confirming that most of $\mathrm{H}$ was bonded to $\mathrm{C}$ [22]. Assuming such a ratio of 3 , the total content of $\mathrm{H}$ bonded to both the $\mathrm{Si}$ and $\mathrm{C}$ determined by IR would be approximately 4 at.\% that is still lower than the total amount of $\mathrm{H}$ analyzed by ERDA (12 at.\%). This supports the idea that molecular hydrogen is trapped in microvoids of the amorphous layer.

Fig. 7 shows high resolution XPS spectra of $C 1$ s and Si 2p regions of SiC coatings grown at $1073 \mathrm{~K}$ on Si substrate using a PSE solution in toluene. A deconvolution with the proportion of each component is also given. The surface of as-deposited $a-\mathrm{SiC}: \mathrm{H}$ film exhibits

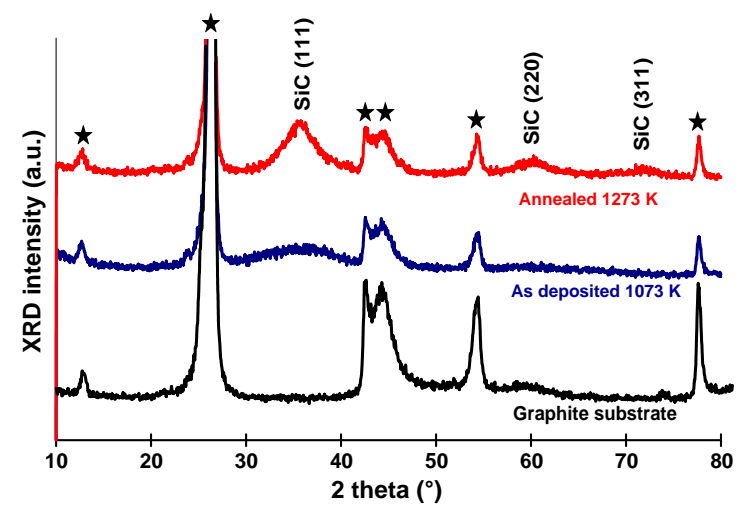

Fig. 5. XRD patterns of SiC coatings as-deposited at $1073 \mathrm{~K}$ on graphite substrate using a PSE solution in toluene and after annealing at $1273 \mathrm{~K}$ under vacuum for $30 \mathrm{~min}$. The XRD pattern of the graphite substrate is also reported.

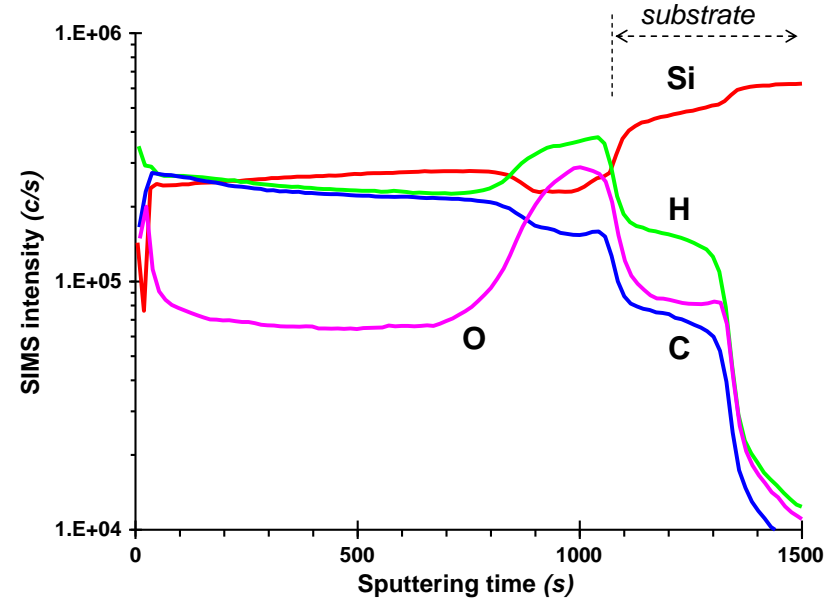

Fig. 6. SIMS profiles of a SiC film grown on silicon by DLICVD using PSE solution in toluene as precursor. The set temperature for the growth was $973 \mathrm{~K}$. The composition determined by EPMA of this sample was $\mathrm{Si}_{0.47} \mathrm{C}_{0.52} \mathrm{O}_{0.01}$.

essentially $\mathrm{C}-\mathrm{C} / \mathrm{C}-\mathrm{H}(42 \%)$ and $\mathrm{Si}-\mathrm{O}(26 \%)$ components and to a lesser extent $\mathrm{C}-\mathrm{O}$ and $\mathrm{Si}-\mathrm{C}$ bonds. This is characteristic of a contamination layer due to the handling of the sample in the ambient atmosphere (Fig. 7a). After in situ cleaning by $\mathrm{Ar}^{+}$sputtering, the XPS spectra of Si 2p and C 1s show an atomic environment more representative of the bulk of the coating (Fig. 7b). No evidence for $\mathrm{Si}-\mathrm{Si}$ bonds was found indicating that there is no phase of Si. Traces of oxygen are bonded to $\mathrm{Si}$ and the main component of $\mathrm{Si} 2 \mathrm{p}$ is due to $\mathrm{Si}-\mathrm{C}$ bonds at $100.6 \mathrm{eV}$ (45\%). Two components are found for the C 1s core level; the carbide $\mathrm{SiC}$ at $283.4 \mathrm{eV}(40 \%)$ and a free $\mathrm{C}$ or an organic form at $284.5 \mathrm{eV}(8 \%)$. The presence of a small amount of free $C$ is consistent with the slight excess of $\mathrm{C}$ found by EPMA for coatings grown using PSE solutions in toluene since the composition was $\mathrm{Si}_{0.45} \mathrm{C}_{0.53} \mathrm{O}_{0.02}$ (Table 3).

Micro-indentation tests were performed on a series of SiC coatings deposited at $1073 \mathrm{~K}$ on Si substrate using PSE solutions in toluene. Their thicknesses were between 5 and $12 \mu \mathrm{m}$. As expected, it was found that the hardness of the coatings decreased by increasing the load as a result of a stronger influence of the substrate. For these samples, the Vickers microhardness determined at low loads was typically $\mathrm{HV}_{0.1}=2300 \pm 50$. The hardness of a couple of $a-\mathrm{SiC}: \mathrm{H}$ coatings as-deposited at 1023 and $1073 \mathrm{~K}$ on silicon was also determined by nano-indention. Their thickness was 5 and $11 \mu \mathrm{m}$, respectively. A hardness of 22 and $23 \mathrm{GPa}$ was found and an elastic modulus of 180 and 190 GPa was measured, respectively.

\section{Discussion}

\subsection{Comparison of pure DSB and PSE precursors}

The two compounds DSB and PSE were previously used in MOCVD (Table 1) and this work demonstrates that they exhibit suitable physical properties (Table 2 ) to be employed directly as liquid precursors in DLICVD processes to produce SiC coatings. Their thermal stability is very similar because when they are used as pure precursors under the same hydrodynamic conditions in a hot-wall CVD reactor, the onset temperature of deposition is equivalent, 910 and $915 \mathrm{~K}$, respectively. This is consistent with their parent structure based on $[\mathrm{Si}-\mathrm{C}]$ backbone that prefigures the formation of $\mathrm{SiC}$ via polymerization and cross linking mechanisms as previously reported [22]. As a result, at the same deposition temperature of $973 \mathrm{~K}$, the coatings grown using these pure precursors exhibit the same surface morphology (Figs. 1a, b and 2a) and an amorphous structure with a stoichiometric composition (Table 3). An increase of the deposition temperature does not change the stoichiometry but this significantly improves 


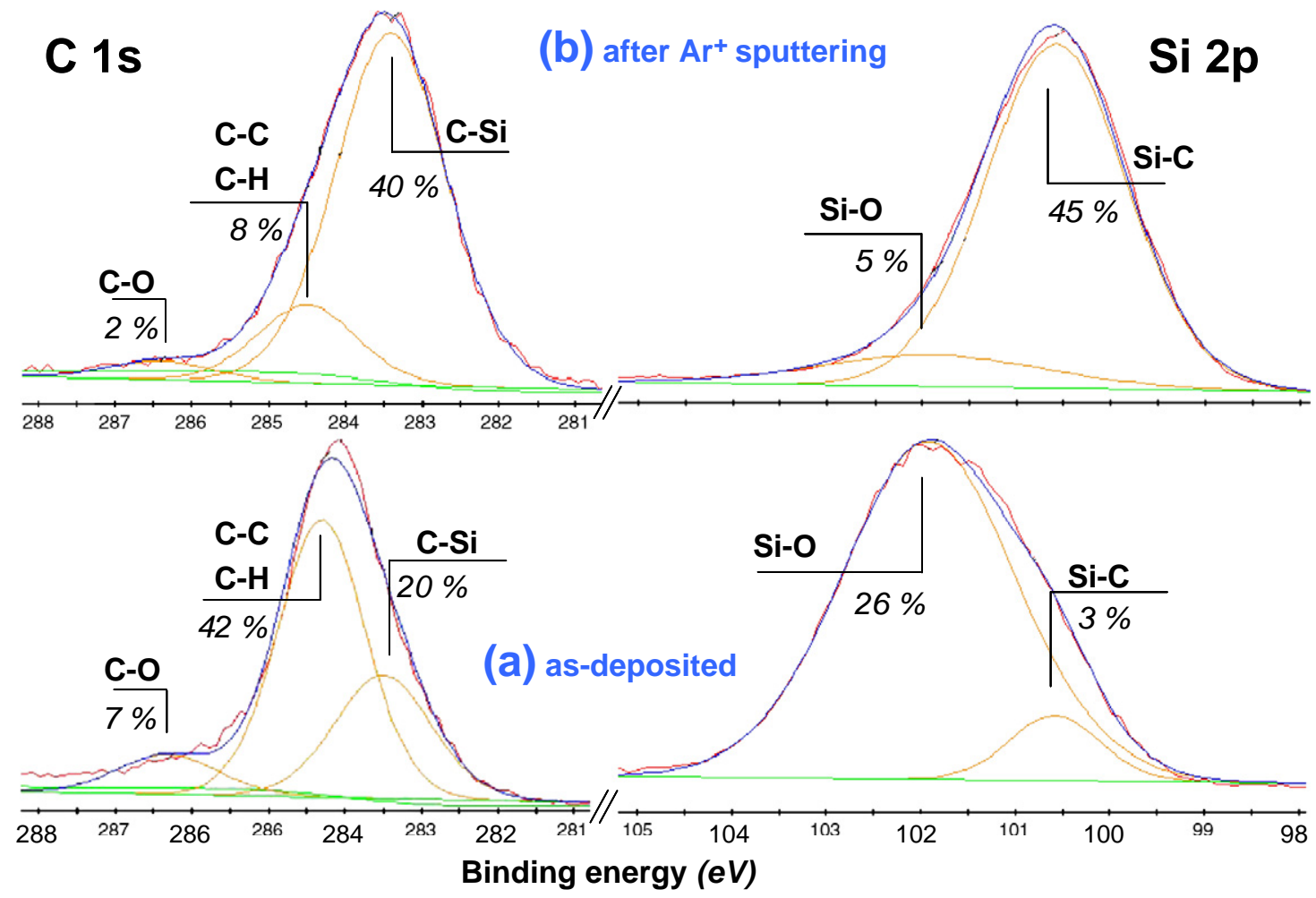

Fig. 7. High resolution XPS spectra of C 1 s and Si 2p regions of SiC coatings grown at $1073 \mathrm{~K}$ on Si substrate using a PSE solution in toluene: (a) as-deposited; (b) after Ar ${ }^{+}$sputtering to clean the surface. The proportion of each component is also indicated.

the microstructure which becomes, for instance at $1073 \mathrm{~K}$, very dense with a smooth surface morphology (Figs. 1c, $d$ and $2 b$ ). This is due to the higher surface diffusion of the adsorbed nutrient species, i.e. the chemical species adsorbed on the growing surface coming from the gas phase that are directly involved in the growth of the layer.

The variation in the growth rate also provides evidence for a similar kinetic behavior of the two precursors (Fig. 3). The deposition rate increases sharply along the first $10 \mathrm{~cm}$ to a maximum near the beginning of the isothermal zone. This indicates that the process is thermally activated because the temperature is increasing in this part. In the isothermal zone, after the maximum, the growth rate decreases slightly due to the depletion of the precursor. At this stage, we have not tried to improve the uniformity of thickness in the reactor axis but this will be possible in future work by modeling of the CVD reactor. For instance, in this tubular isothermal CVD reactor, a simple 1D model has been used previously to optimize the thickness uniformity of Ni films [27]. Obviously, more complex 2D and 3D simulations of $\mathrm{SiC}$ growth could be applied for a complete understanding of the process as reported for a horizontal hot-wall CVD reactor using $\mathrm{SiH}_{4} / \mathrm{C}_{3} \mathrm{H}_{8}$ as precursors [28]. In this objective, a key point is the knowledge of the chemical mechanisms and kinetics of the process. From this point of view, our results will be a first set of experimental data.

The fact that a very high growth rate was measured and a 1:1 Si:C ratio was analyzed in the coatings as in the two precursors suggest that the mechanism previously reported for pyrolytic conversion to $\mathrm{SiC}$ holds also in CVD processes. Indeed, in pyrolytic experiments, it was demonstrated that the decomposition occurs essentially by $\mathrm{H}_{2}$ loss leading to a high ceramic yield of $c a$. 85\% rather than by cleavage of $\mathrm{Si}-\mathrm{C}$ bonds which would release light organic by-products [22].

These precursors also provide a high yield of the CVD process as supported by the high values of the maximum growth rate, 60 and $90 \mu \mathrm{m} \cdot \mathrm{h}^{-1}$ for pure DSB and PSE, respectively. This is consistent with a high apparent ceramic yield as previously reported [22]. The maximum growth rate is approximately $50 \%$ higher for PSE and slightly less on average along the reactor. This difference between the two precursors seems important but it is mainly due to the difference in the mass balance rather than different kinetics and reaction pathways. Indeed, for the data of Fig. 3, if the injection conditions ( $2 \mathrm{~Hz}, 0.5 \mathrm{~ms}$ ), the deposition temperature $(973 \mathrm{~K})$, total flow rate $\left(500 \mathrm{sccm} \mathrm{N} \mathrm{N}_{2}\right.$ ) and total pressure $(6.7 \mathrm{kPa})$ were the same using pure DSB and PSE, on the contrary the duration of the run (10 and $20 \mathrm{~min}$, respectively), the density (Table 2 ) and the molecular weight of the precursors were different. An estimation of the molecular flow rate of $[\mathrm{Si}-\mathrm{C}]$ units provided by each precursor can be determined from their molecular weight and the empirical formula of linear polycarbosilanes $(\mathrm{Si}-\mathrm{C})_{\mathrm{x}} \mathrm{H}_{4 \mathrm{x}+2}$. Ideally, $1 \mathrm{~mol}$ of precursor provides $\mathrm{x}$ moles of $[\mathrm{Si}-\mathrm{C}]$ units and it is deduced that $\mathrm{x}=(\mathrm{M}-2) / 44$, where $\mathrm{M}$ is the molecular weight of the precursor. Assuming a very narrow molecular weight distribution for PSE $\left(M_{w} / M_{n}=1 ; M_{n}=\right.$ 2000) $[13,14,22]$, the $x$ values are 45 for PSE and only 2 for DSB. Using the molecular flow rate of precursors calculated by the Eq. (1), the molecular flow rates of $[\mathrm{Si}-\mathrm{C}]$ units delivered using DSB and PSE are $3.96 * 10^{-3}$ and $5.04 * 10^{-3} \mathrm{~mol} \cdot \mathrm{min}^{-1}$, respectively. The excess of $[\mathrm{Si}-\mathrm{C}]$ units of approximately $27 \%$ starting from PSE accounts for the higher growth rate found using this precursor.

\subsection{Starting with PSE solutions in toluene: effect of the solvent}

SiC coatings grown at $973 \mathrm{~K}$ using PSE solutions in toluene exhibit a very smooth surface morphology compared to those deposited using pure precursor (Fig. 2c-e). In presence of toluene, there is a surfactant effect during the growth which leads to a surface morphology similar to that obtained without toluene but at a deposition temperature greater than $100^{\circ}$ (Fig. 1c, d). Surfactant assisted-CVD processes have been reported $[29,30]$. Such processes have been used for instance to improve the filling of narrow trenches in metallization of microelectronic devices [31]. It is well known that a 3D island growth mode can be switched to a layer-by-layer growth mode using adsorbed species which act as surfactant to enhance the nucleation 
density and the surface mobility of the deposited atoms by lowering the surface free energy [32]. Here we found evidence that toluene promotes the lateral growth to significantly decrease the surface roughness and then it acts as a volatile surfactant.

Another evidence that toluene is involved in the growth mechanism is given by the slight excess of carbon in the coatings deposited in the low temperature range of $973-1073 \mathrm{~K}$ since the $\mathrm{Si}: \mathrm{C}$ ratio of the film passes from 1:1 without toluene to $1: 1.2$ with the solvent (Table 3). Although the growth rate changes along the reactor (Fig. 4), the film composition is constant and independent on the coordinate of the samples for temperatures lower than $1073 \mathrm{~K}$ (Table 3). Although toluene was reported to be thermally stable below $1073 \mathrm{~K}$ [33], it contributes to an increase of the $C$ concentration in the coatings but there is no evidence that the $C$ excess originates directly from the toluene decomposition at temperatures lower than $1073 \mathrm{~K}$. The toluene stability was confirmed by specific experiments in this DLICVD reactor. Indeed, when pure toluene was injected at $1073 \mathrm{~K}$ a very thin, light gray and transparent film of pyrocarbon was formed on the reactor wall while no significant decomposition was found at lower temperatures. Consequently, for SiC grown using PSE solution in toluene at $1073 \mathrm{~K}$, the $\mathrm{C}$ content is increased along the reactor axis to 65 at.\% C in the second half, while it is constant at lower temperature ( 55 at.\% C), indicating that pyrolysis of toluene likely occurs for $\mathrm{T} \geq 1073 \mathrm{~K}$ and contributes to $\mathrm{C}$ incorporation in the coatings (Table 3 ).

The role of toluene at temperatures lower than $1073 \mathrm{~K}$ is less clear. When it is adsorbed on the surface of the growing film it likely acts as a surfactant. However its concentration in the gas phase is much higher than that of the PSE precursor and it can be involved in homogenous reactions. For instance, it was used previously as free radical scavenger in MOCVD to highlight radical mechanisms by changing the kinetics of the process $[33,34]$. By reacting with radicals from the precursor it increases the decomposition temperature by a retardation of pyrolysis [34]. On the other hand, the thermal decomposition of PSE was reported to be a free radical process for temperatures higher than $748 \mathrm{~K}$ [22]. Consequently a radical mechanism likely occurs in the DLICVD reactor in the temperature range of 923-1073 K. A study on the pyrolysis of PSE had demonstrated that this compound was completely decomposed at $c a .923 \mathrm{~K}$ to form a 3D network structure [22]. This is consistent with the onset temperature of deposition found at $915 \mathrm{~K}$ for pure PSE (Fig. 3). We cannot compare with the onset temperature of deposition using PSE solution in toluene to see a possible effect of the solvent because we were not able to determine precisely this temperature. However, for CVD runs at $973 \mathrm{~K}$, we observed a shift of the maximum growth rate from $c a$. $25 \mathrm{~cm}$ (Fig 3) to ca. $45 \mathrm{~cm}$ (Fig. 4) using pure PSE and PSE solution in toluene, respectively. This shift can be due to a hydrodynamic effect but the presence of radical scavengers in the mechanism can also be a cause. From the dwelling time of the chemical species in the reactor, we determined the time required to reach the maximum growth rate as 1.1 and $1.3 \mathrm{~s}$, respectively. The longer time in presence of toluene argues for a radical scavenger effect. Of course this is not a final confirmation and further study on the mechanism is necessary.

A small amount of hydrogen is incorporated in the coatings. Regardless of the deposition temperature in the range of 973-1073 K, the $\mathrm{Si}-\mathrm{H}$ stretching mode is found at $2103 \mathrm{~cm}^{-1}$ that is higher than isolated monohydride modes $\left(\mathrm{Si}_{3-\mathrm{x}} \mathrm{C}_{\mathrm{x}}\right) \mathrm{Si}-\mathrm{H}$ expected at $\mathrm{ca} .2000 \mathrm{~cm}^{-1}$ for $\mathrm{x}=0$ or 1 , and at $c a .2060 \mathrm{~cm}^{-1}$ for $\mathrm{x}=2$ or 3 [35]. This absorption band could be attributed either to dihydride $\mathrm{SiH}_{2}$ modes with or without $C$ as neighbor atoms or to clustered monohydrides [24,35,36]. Interestingly, these modes are a feature of hydrogenation of internal surfaces of microvoids as reported for $a-\mathrm{Si}: \mathrm{H} \mathrm{[24]} \mathrm{and} a-\mathrm{SiC}: \mathrm{H}$ [36]. This supports the existence of microvoids in the DLICVD coatings. They can trap molecular hydrogen in the $\mathrm{H}$ release process leading to a 3D SiC network. The presence of molecular hydrogen is supported by the difference between ERDA and IR analyses.

\subsection{Preliminary mechanical properties}

The Vickers microhardness of $a$-SiC:H DLICVD coatings deposited on $\mathrm{Si}(100)$ at $1073 \mathrm{~K}$ is $\mathrm{HV}_{0.1}=2300 \pm 50$ that is slightly lower than that of SiC coatings grown on the same substrate at $973 \mathrm{~K}$ by activated reactive evaporation, which were also C-rich (C:Si 1.17 compared to 1.22 ) but these $\mathrm{SiC}$ coatings were polycrystalline while the DLICVD coatings are amorphous [37]. The high value of nanohardness (23 GPa) confirms that they are hard coatings and not inorganic polymer materials.

In CVD processes, significant residual stresses $\left(\sigma_{\mathrm{r}}\right)$ are expected in the coatings due to the contribution of both thermal $\left(\sigma_{\text {th }}\right)$ and intrinsic $\left(\sigma_{\mathrm{i}}\right)$ stresses. Observation of many cracks in SiC coatings is consistent with high tensile residual stresses which facilitate the opening and propagation of cracks. The thermal stresses can be determined according to Eq. (2):

$\sigma_{\mathrm{th}}=\left(\alpha_{\mathrm{SiC}}-\alpha_{\mathrm{s}}\right) * \Delta \mathrm{T} * \mathrm{E}_{\mathrm{SiC}} /\left(1-v_{\mathrm{SiC}}\right)$

where $\mathrm{E}_{\mathrm{SiC}}, \nu_{\mathrm{SiC}}$ and $\alpha_{\mathrm{SiC}}$ are the Young modulus (240 GPa), the Poisson's ratio (0.2) and the thermal expansion coefficient $\left(\alpha_{\mathrm{Sic}}=\right.$ $4.5 * 10^{-6} \mathrm{~K}^{-1}$ ) [38] of SiC films [39], $\Delta \mathrm{T}$ is the difference of temperature and $\alpha_{\mathrm{s}}$ is the thermal expansion coefficient of the substrate $\left(\alpha_{\mathrm{Si}}=2.5 * 10^{-6} \mathrm{~K}^{-1}[40]\right.$ and $\left.\alpha_{\text {graphite }}=6.0 * 10^{-6} \mathrm{~K}^{-1}\right)$. For instance at $1073 \mathrm{~K}$, tensile $(+465 \mathrm{MPa})$ and compressive $(-349 \mathrm{MPa})$ thermal stresses were calculated for the coatings on $\mathrm{Si}$ and graphite, respectively. Since many cracks are observed on the two substrates, we assume that $a$-SiC:H coatings are in tension, i.e. $\sigma_{\mathrm{r}}=\sigma_{\mathrm{th}}+\sigma_{\mathrm{i}}<0$. Assuming that the intrinsic stresses are the same regardless of the substrate, high tensile intrinsic stresses are expected to compensate the compressive thermal stress of the coatings on graphite. This dominant tensile intrinsic stress is induced by the growth mechanism and more precisely by the densification of the coatings resulting from the release of residual hydrogen from the growing SiC layer.

\section{Conclusions}

Amorphous SiC coatings were deposited by DLICVD at $973 \mathrm{~K}$ $\left(700{ }^{\circ} \mathrm{C}\right)$ using the organosilanes DSB and PSE as pure liquid precursors. These coatings retain the $1: 1 \mathrm{Si}: \mathrm{C}$ atomic ratio of the molecular precursors. The high growth rates obtained are consistent with a high yield of the DLICVD process using these single-source precursors. This is in good agreement with the high ceramic yield found in pyrolytic conversion to $\mathrm{SiC}$ [22]. Indeed, the decomposition mechanism essentially proceeds by $\mathrm{H}_{2}$ release via a free radical mechanism. This mechanism also seems to occur in a CVD reactor. Both precursors exhibit the same kinetic behavior leading for instance to an equivalent variation of the growth rate along a horizontal hot-wall CVD reactor. At $973 \mathrm{~K}$, the coatings have a nodular surface morphology, a high surface roughness and low density. At $1073 \mathrm{~K}$, the surface morphology becomes smooth, the structure is dense and a network of microcracks is more visible.

C-rich (54 at.\% C) and amorphous SiC coatings were deposited by this process in the temperature range of 923-1073 K using PSE solutions in toluene. The vapor of the solvent acts as surfactant because very smooth surface morphologies were observed at low temperature (973 K). Although toluene was reported to be stable below $1073 \mathrm{~K}$, it is involved in the decomposition mechanism of PSE, possibly as free radical scavenger, and it contributes to a slight increase of the $C$ concentration in the coatings. Beyond $1073 \mathrm{~K}$, toluene undergoes a pyrolysis that increases more significantly the $C$ incorporation into the films (65 at.\% C). These hard coatings exhibit many cracks likely due to high tensile intrinsic stresses induced by the growth mechanism that is essentially a densification with hydrogen release from the growing layer. These intrinsic stresses are dominant compared to the thermal stresses. 
This work demonstrated that a PSE solution in toluene is a good candidate as a liquid precursor for DLICVD of SiC in large scale reactor. Investigation on the mechanism and modeling of the growth rate are currently in progress to improve the thickness uniformity in the reactor axis.

\section{References}

[1] G. Dhanaraj, M. Dudley, Y. Chen, B. Raghothamachar, B. Wu, H. Zhang, J. Cryst. Growth 287 (2006) 344.

[2] J.A. Powell, D.J. Larkin, L.G. Matus, W.J. Choyke, J.L. Bradshaw, L. Henderson, M. Yoganathan, J. Yang, P. Pirouz, Appl. Phys. Lett. 56 (1990) 1442

[3] M.D. Allendorf, R.J. Kee, J. Electrochem. Soc. 138 (1991) 841

[4] A. Josiek, F. Langlais, X. Bourrat, Chem. Vap. Depos. 2 (1996) 17

[5] F. Loumagne, F. Langlais, R. Naslain, S. Schamm, D. Dorignac, J. Sévely, Thin Solid Films 254 (1995) 75

[6] J. Hofmann, S. Veprek, Thin Solid Films 318 (1998) 18

[7] F. Maury, Chem. Vap. Depos. 2 (1996) 113.

[8] F. Maury, A. Mestari, R. Morancho, Mater. Sci. Eng. A 109 (1989) 69.

[9] J.M. Agullo, F. Fau-Canillac, F. Maury, J. Mater. Chem. 4 (1994) 695

[10] F. Maury, J.M. Agullo, Surf. Coat. Technol. 76-77 (1995) 119

[11] W.-C. Lien, N. Ferralis, C. Carraro, R. Maboudian, Cryst. Growth Des. 10 (2010) 36

[12] J.H. Boo, K.-S. Yu, Y. Kim, S.H. Yeon, I.N. Jung, Chem. Mater. 7 (1995) 694.

[13] (See the web site) www.starfiresystems.com.

[14] Q.-M. Cheng, L.V. Interrante, M. Lienhard, Q. Shen, Z. Wu, J. Eur. Ceram. Soc. 25 (2005) 233.

[15] F. Felten, J.P. Senateur, F. Weiss, R. Madar, A. Abrutis, J. Phys. IV Collq. C5 (1995) 1079 .

[16] G. Boisselier, F. Maury, F. Schuster, J. Nanosci. Nanotechnol. 11 (2011) 8289.

[17] F. Maury, A. Douard, S. Delclos, D. Samelor, C. Tendero, Surf. Coat. Technol. 204 (2009) 983.

[18] Y.S. Li, S. Shimada, Surf. Coat. Technol. 201 (2006) 1160.

[19] J. Selvakumar, D. Sathiyamoorthy, K.S. Nagaraja, Surf. Coat. Technol. 205 (2011) 3493.
[20] J.W. Brockmeyer, B.E. Williams, in: A. Kumar, Y.-W. Chung, R.W.J. Chia (Eds.), Hard Coatings Based on Borides, Carbides and Nitrides, The Minerals, Metals \& Materials Society, 1998, p. 259.

21] See the web site www.gelest.com.

22] Q. Liu, H.J. Wu, R. Lewis, G.E. Maciel, L.V. Interrante, Chem. Mater. 11 (1999) 2038

[23] W.C. Oliver, G.M. Pharr, J. Mater. Res. 7 (1992) 1564.

[24] W.A. Lanford, M.J. Rand, J. Appl. Phys. 49 (1978) 2473.

[25] A. Guivarc'h, J. Richard, M. LeContellec, E. Ligeon, J. Fontenille, J. Appl. Phys. 51 (1980) 2167.

26] U. Kroll, J. Meier, A. Shah, S. Mikhailov, J. Weber, J. Appl. Phys. 80 (1996) 4971.

[27] F. Fau-Canillac, F. Maury, Surf. Coat. Technol. 64 (1994) 21.

[28] J. Meziere, M. Ucar, E. Blanquet, M. Pons, P. Ferret, L. Di Cioccio, J. Cryst. Growth 267 (2004) 436.

29] A.A. Molodyk, I.E. Korsakov, M.A. Novojilov, I.E. Graboy, A.R. Kaul, G. Wahl, Chem Vap. Depos. 6 (2000) 133.

[30] E.S. Hwang, J. Lee, Chem. Mater. 12 (2000) 2076.

[31] Y. Au, Y. Lin, R.G. Gordon, J. Electrochem. Soc. 158 (2011) D248.

[32] H.L. Meyerheim, D. Sander, R. Popescu, W. Pan, I. Popa, J. Kirschner, Phys. Rev. Lett. 99 (2007) 116101.

[33] J. El Boucham, M. Amjoud, R. Morancho, F. Maury, A. Yacoubi, Ann. Chim. Sci. Mater. 23 (1998) 381

[34] C.A. Larsen, N.I. Buchan, S.H. Li, G.B. Stringfellow, J. Cryst. Growth 102 (1990) 103

[35] N.K. Huang, B. Yang, Q. Xiong, Y.G. Liu, D.Z. Wang, J.R. Lei, Nucl. Inst. Methods Phys. Res. B 195 (2002) 344

[36] M. Katiyar, Y.H. Yang, J.R. Abelson, J. Appl. Phys. 78 (1995) 1659

[37] Y.H.C. Cha, G. Kim, H.J. Doerr, R.F. Bunshah, Thin Solid Films 253 (1994) 213.

[38] Z. Li, R.C. Bradt, J. Mater. Sci. 21 (1986) 4366.

[39] M.A. El Khakani, M. Chaker, A. Jean, S. Boily, J.C. Kieffer, M.E. O'Hern, M.F. Ravet, F. Rousseaux, J. Mater. Res. 9 (1994) 96.

[40] A. Bergamin, G. Cavagnero, G. Mana, G. Zosi, J. Appl. Phys. 82 (1997) 5396.

[41] W.L. Liu, H.R. Xia, X.Q. Wang, H. Han, P. Zhao, Y.B. Lü, S.Q. Sun, Y.M. Wang, H.G. Yoon, J.H. Boo, S.B. Lee, S.C. Park, H. Kang, Thin Solid Films 461 (2004) 266.

[42] (See the web site) www.sigmaaldrich.com.

[43] F.J.V. Santos, C.A.N. de Castro, J.H. Dymond, N.K. Dalaouti, M.J. Assael, A. Nagashima, J. Phys. Chem. Ref. Data 35 (2006) 1. 